\title{
Using a Paper-Based Supply Chain Game to Enhance Student Learning with Enterprise Software
}

\section{Mr. Scott Abney, East Carolina University}

Scott Abney is currently an Assistant Professor at East Carolina University while completing his Ph.D. in Industrial Engineering Technology from Purdue University. Scott has previously obtained a Master of Science in Industrial Technology from Purdue as well as a Bachelor of Arts in Political Science from Eastern Kentucky University. Scott currently teaches the Introduction to Distribution and Logistics course at East Carolina University. His research interests are: supply chain management, sustainability, lean manufacturing, and ERP system integration in curriculum.

\section{Dr. Mark Angolia, East Carolina University}

Mark G. Angolia is an Assistant Professor of Industrial Distribution and Logistics in the College of Engineering and Technology at East Carolina University. Entering academia after 20 years in the automotive supply chain, his research interests include ERP systems, technology management applications for distribution and logistics, and higher education pedagogy. He holds a PhD in Technology Management from Indiana State University, a Master of Engineering from Rensselaer Polytechnic Institute, professional certifications of CPIM and CSCP from APICS, and a PMP from PMI. Dr. Angolia also conducts consulting projects and professional development seminars for local industry on topics including forecasting, inventory control, production planning, project management, transportation logistics, procurement, and supply chain management.

\section{Dr. Leslie Pagliari, East Carolina University}

Dr. Leslie Pagliari serves as Associate Dean for Academic Affairs in the College of Engineering and Technology and Associate Professor in the Department of Technology Systems. Her research interests center on STEM initiatives, leadership, global supply chain issues, and new technologies in the distribution and logistics sector. She was one of three professors in the United States recognized in an Inbound Logistics Article featuring leading professors in today's supply chain curriculum.

She has worked with a team of colleagues throughout other colleges at East Carolina University to plan a STEM initiative for 8th grade girls. This initiative helps bring more than 100 Pitt County girls to campus to engage them in Science, Technology, Engineering, and Math. She has also worked with ECU's Global Academic Initiatives to collaborate with other institutions throughout the world.

In addition, Dr. Pagliari collaborates with many external organizations. She is past president of APICS (Association of Operations Management) and past Education Chair for the CSCMP (Council of Supply Chain Management Professionals). She also served as a board member for the Museum of the Marine in Jacksonville, NC and the Eastern Carolina Safety and Health School. She continues to serves on multiple organizations with the University, College, and Department. Dr. Pagliari was selected and completed the BRIDGES Academic Leadership for Women hosted by UNC-Chapel Hill and was recently nominated for the Women of Distinction award at East Carolina University. 


\section{Using a Paper-Based Supply Chain Game to Enhance Student Learning with Enterprise Software}

Introduction

One particular method of educating students on business processes is through the use of computerized simulations [1]. Research suggests that the 18 to 22-year-old higher education student demographic from Generation Z, born 1995 to 2012 [2], gravitates to activity-based learning that merges theory with some type of immediate gratification [3]. Further, literature suggests that students appear to learn best when using technology that allows them to actively develop knowledge through a combination of experience, structured interaction, and interpretation [4]. Simulations are a complex type of active learning, and when used in higher education, the goal for the instructor is to create the right balance and synergy between course pedagogy and students to affect engagement [5].

In the pedagogical sense, simulations may also be seen as a form of Problem Based Learning (PBL) due to requirements for discovery, versus prescription of knowledge [6]. PBL typically begins with presentation of a problem followed by instructor interaction to lead students to "discover" course concepts and knowledge as they work to solve the problem. The goal is a richer and longer-lasting learning experience than a lecture-based approach. Use of PBL helps students experience realistic cases and not just theoretical scenarios, forcing them to define problems and make proper decisions [7]. This approach shows strong support for a pedagogy's positive impact on student attitude, being more nurturing and enjoyable than traditional means [9]. In summary, PBL advantages include: 1) increased motivation, 2) enhanced learning, retention, and recall, and 3) development of problem solving and self-directed learning abilities [8], [9].

A research area identified focuses on how higher education has had to identify pedagogical advances in ways of teaching concepts and processes related to enterprise resource management (ERP) systems [9]. Cronan and Douglas [10] stated that a challenge exists for instructors to teach, and students to learn, business processes through means engaging live commercial software environments, since students often lack knowledge of real-world business processes [11]. The term "business process" for this paper is defined as a series of steps undertaken by nondirect-labor staff to produce an output, typically a business-related transaction or document. Previous research indicated that introducing concepts before the engagement of hands-on exercises or cases with software has been thoroughly under-addressed [6]. This gap has been identified as being critical to student development since students need to have a basic understanding of business processes and their cross-functional nature before then can fully understand and gain knowledge from hands-on experience [6], [12]. Literature suggests the following key principles and success factors for using simulations in business management related courses: [13]

1. Develop students' understanding of business process complexity and dynamics

2. Utilize decision making in different, challenging situations in a time-based environment 
3. Allow students to experience cross-functional information sharing in a silo-based structure

4. Measure performance against benchmarks and peers

The purpose of this paper is to show the effectiveness of using a paper-based supply chain simulation as an introductory tool for teaching fundamental business processes as a foundation for coursework utilizing software to teach ERP and related information technology concepts.

Background

As ERP software continues to expand into the business world, employers and higher education institutes must adapt training of employees and students to meet this challenge [14]. Many Fortune 1000 organizations have adopted ERP into their organizational operations, which in turn has kick-started the evaluation and redesign of business processes [6], [9], [14]. Consequently, the demand for graduates who have hands-on experience with ERP software has increased significantly [14]. More so, graduates who have completed ERP coursework have seen a nearly a $\$ 4,000$ higher average salary than their peers who have no ERP experience [10]. This is comparable to previous research that has shown career success regarding salaries and promotions for students related to performance on simulations [8].

An effective set of simulations to develop student knowledge of business process and ERP systems has been developed by the ERPsim Lab at HEC Montreal https://erpsim.hec.ca/en. The ERPsim Lab has a suite of business simulations using a live SAP ERP software environment accessed through the SAP University Alliance (UA). The SAP UA has over 3,200 member institutions worldwide from over 110 different countries; more than 130 universities across 16 countries have incorporated the ERPsim Lab's innovative teaching tools [8]. As an introductory tool, the ERPsim Lab also developed a manual (non-software based) "paper game" to introduce business processes and concepts to students before engagement with the more complex software based simulations.

The paper game uses sheets of paper as a raw material to produce a product within a simple three-tier supply chain. Students manage the manufacturing company at the center of the chain, with a single downstream customer and single upstream supplier, managing functional areas of sales, materials management (purchasing and logistics), manufacturing, and accounting. For PBL and active learning, students are placed into teams of four, with each assigned to a functional management role. The simulation is played on a virtual week-by-week basis, repeating a series of steps that also incorporate the materials requirement planning (MRP) heuristic:

1. Raw materials are received (MRP recognizes receipts at the start of a time bucket)

2. Finished goods market price determined

3. Sales order created: initiates productionlconsumption of raw materials within time bucket

4. Delivery of finished goods; customer invoice generated

5. Customer payment received for shipments two time buckets prior

6. Raw material market price determined

7. Purchase order for raw material created (based on ending inventory at end of time bucket) 
The game is played over 10 rounds, each equal to a simulated week. Each "week" generally takes ten minutes at the start of the game, reducing to about 5 minutes as students progress up a learning curve. The game is played over several class hours with pauses to reinforce teaching concepts. Teams are provided templates to create business documents onto post-it notes. External documents such as purchase orders and invoices are written and placed onto large (customer or supplier) game boards to track activity. Sales orders, as internal documents, are passed from sales to manufacturing to accounting as the primary communication tool. The instructor uses playing cards to determine random weekly market sales prices and raw material cost, and also generates post-it notes to represent customer payment. In support of this study, an Excel spreadsheet, shown in Figure 1, is provided and each functional manager asked to keep track of information as the game is played.

\begin{tabular}{|l|l|l|l|l|l|l|l|l|l|l|l|l|}
\hline Sales Week & $\mathbf{1}$ & $\mathbf{2}$ & $\mathbf{3}$ & $\mathbf{4}$ & $\mathbf{5}$ & $\mathbf{6}$ & $\mathbf{7}$ & $\mathbf{8}$ & $\mathbf{9}$ & $\mathbf{1 0}$ & Total & Ave \\
\hline Market Price & & & & & & & & & & & \\
\hline Units Sold & & & & & & & & & & & & \\
\hline Revenue (total sale) & & & & & & & & & & & & \\
\hline
\end{tabular}

\begin{tabular}{|l|l|l|l|l|l|l|l|l|l|l|l|l|}
\hline Purchasing Week & $\mathbf{1}$ & $\mathbf{2}$ & $\mathbf{3}$ & $\mathbf{4}$ & $\mathbf{5}$ & $\mathbf{6}$ & $\mathbf{7}$ & $\mathbf{8}$ & $\mathbf{9}$ & $\mathbf{1 0}$ & Total & Ave \\
\hline Market Cost for a Sheet of Paper & & & & & & & & & & & & \\
\hline Purchase Quantity & & & & & & & & & & & & \\
\hline Total Expense & & & & & & & & & & & & \\
\hline
\end{tabular}

\begin{tabular}{|l|l|l|l|l|l|l|l|l|l|l|l|l|}
\hline Manufacturing | Week & $\mathbf{1}$ & $\mathbf{2}$ & $\mathbf{3}$ & $\mathbf{4}$ & $\mathbf{5}$ & $\mathbf{6}$ & $\mathbf{7}$ & $\mathbf{8}$ & $\mathbf{9}$ & $\mathbf{1 0}$ & Total & Ave \\
\hline Production (sections of paper cut) & & & & & & & & & & & & \\
\hline Ending Inventory (finished units) & & & & & & & & & & & & \\
\hline
\end{tabular}

\begin{tabular}{|l|c|c|c|c|c|c|c|c|c|c|c|}
\hline Accounting Week & $\mathbf{1}$ & $\mathbf{2}$ & $\mathbf{3}$ & $\mathbf{4}$ & $\mathbf{5}$ & $\mathbf{6}$ & $\mathbf{7}$ & $\mathbf{8}$ & $\mathbf{9}$ & $\mathbf{1 0}$ & Total \\
\hline Invoice to Customer & & & & & & & & & & & \\
\hline Invoice from Supplier & & & & & & & & & & & \\
\hline Cash on Hand & 10 & & & & & & & & & & \\
\hline
\end{tabular}

Figure 1. Paper Game Manual Data Tracking Spreadsheet

Raw material is a blank sheet of paper and the manufacturing process is a pair of scissors used to cut the paper into six sections. Teams may sell as many finished goods as they can produce and have on-hand in inventory. Raw material may be purchased but only in limited quantity, and only if they have enough cash on hand to pay the supplier's invoice when due. Students place post-it note invoices onto the current week in the customer game board, and collect payment from the board two weeks later. Purchase orders (PO) post-it notes are placed on the supplier game board, a post-it note payment is placed over top of the PO the following week as the materials manager receives the sheet(s) of paper purchased. Accounting writes all invoices and supplier payments, and must track cash-on-hand.

At the midway point in the simulation, the game takes a time-out as teams are asked to analyze information they (should) have been collecting. Requested analysis includes averages on sales 
price per case, weekly demand, and average raw material cost. Teams are also asked to identify their current finished goods inventory, accounts payable, accounts receivable, and profit. Averages are to be calculated, with teams encouraged to think about how averages may be used to forecast for the balance of the game. The intent of this break is for students to appreciate how businesses need to collect information in order to make decisions.

The second half of the simulation continues like the first half with the exception of week 9. During week 9 teams are informed of a supply chain disruption and are not allowed to purchase raw material for the balance of the game. At the end of week 10 students were asked to update the information from week 5 and draw a business process flow chart based on their experience in the simulation. Students are also asked to update their Excel spreadsheets and are not allowed to review any post-it notes that are not at their own workstation. In the post simulation review, which is the most critical learning aspect of the game, the business processes are reviewed to ensure the information flow and transactional concepts are understood. Also, the instructor asks each functional manager to report average market sales price and raw material cost. While this should be the same for each team, empirical evidence shows that it is usually not, providing a segue into discussion on the importance of data accuracy and the value of information technology.

\section{Research Method}

The research site was an undergraduate introductory course on ERP systems, intended to expose students to information technology used to manage business processes. The course utilizes a live SAP ERP environment to demonstrate the software and tools used within the distribution channel of a supply chain. Inherent in this is understanding the business processes needed to manage sales, materials, production, and warehousing. The paper game is used as an active learning technique within an introductory module during the first two class weeks. The active nature of game also serves as a tool for students to meet and engage with each other, providing a foundation for peer-to-peer assistance throughout the course.

The focus of the study is student self-assessment of knowledge learned after playing the simulation versus the self-assessment prior to playing the simulation. The survey also contained questions regarding student attitudes toward the simulation and instructor. Data was collected via a Qualtrics survey immediately after the post simulation review to limit influence from further coursework. The data collection spanned two academic years, encompassing three class sections during spring 2017, fall 2017, and spring 2018. Students were informed that responses were anonymous and had no impact on their course grade.

\section{Results and Discussion}

The total number of survey participants was 48 students. Table 1 summarizes the effectiveness of instructor, simulation, and introduction of business processes. Responses were coded using a Likert scale with 5 representing the high end of the scale, 3 as neutral, and 1 as a negative perception. For instructor effectiveness, over half of all respondents felt the instructor was "extremely effective" on use of the paper game simulation. Again, over half the students rated the simulation as "extremely effective" in helping understand business process concepts. 
Furthermore, it should also be noted that the highest rated mean (4.68) was observed and lowest standard deviation (0.47) are associated with the simulation's ability to help students understand the business processes.

Overall it seemed that student feedback was relatively consistent and students both liked and found the simulation engaging. In both instances, over $50 \%$ of students responded with "like a great deal" and "very engaging" respectively. This is critical due to previous research concluding in order for simulations to be effective, students must both enjoy the simulation as well as find the simulation engaging [6], [10]. Students also stated that they believed the objectives of the simulation were "clear." The importance of instructor effectiveness cannot be downplayed as research has stated that for students to gain max enjoyment and benefits of simulation, they must "buy-in" to the instructor and the instructor's teaching methods [6], [10], [13].

Table 1. Student Perception of Simulation Effectiveness $(n=48)$

\begin{tabular}{|l|c|c|c|}
\hline \multicolumn{1}{|c|}{ Question } & Mean & Median & Std. Dev. \\
\hline 1. Did you like the simulations? & 4.43 & 5.00 & 0.65 \\
\hline 2. Did you find the simulation engaging? & 3.87 & 4.00 & 0.82 \\
\hline 3. Were the simulation objectives clear? & 4.09 & 4.00 & 0.69 \\
\hline 4. Was the instructor effective in using the simulation? & 4.35 & 5.00 & 1.00 \\
\hline 5. Did the simulation help you understand course material? & 4.68 & 5.00 & 0.47 \\
\hline
\end{tabular}

Table 2 displays descriptive statistics of student self-assessment of understanding terminology and processes before and after participating in the simulation. Responses were coded using a Likert scale with 3 representing "very proficient," 2 as "somewhat," and 1 as "not proficient." Zero represented "no knowledge or understanding" of a concept. Students were very open in their pre-simulation assessment, admitting to being "not proficient" in many of the categories associated with the topics covered in the simulation. The highest rated pre-assessment was regarding sales and distribution terminology with a mean of 1.61, placed squarely between somewhat- and not-proficient. Students self-rated lowest for the "importance of integrated business processes via ERP" at 0.87 , which is to be expected as most students were unfamiliar with ERP systems before enrolling in the course.

For the post-simulation self-assessment, all students recorded an increase in ratings. Literature suggests that when conducting self-assessments, students may often view their ability higher than the reality of attainment [15]. Interestingly, this study's results were somewhat muted in this respect. Surprisingly, although perhaps an honest appreciation for what they didn't know, none of the question means observed showed students believing they have achieved "very proficient" status in any category. Over half the class surveyed believed that their abilities firmly rated into being "somewhat proficient." This is interesting as one critique of student self-assessment has been students having higher confidence in their abilities then what may be a reality [6]. 
Table 2. Descriptive Statistics for Business Concepts ( $\mathrm{n}=48$ )

\begin{tabular}{|l|c|c|c|c|c|c|}
\hline \multicolumn{1}{|c|}{$\begin{array}{c}\text { Student Proficiency Self-Assessment } \\
\text { (knowledge and skills) }\end{array}$} & \multicolumn{2}{c|}{ Mean } & \multicolumn{2}{c|}{ Median } & \multicolumn{2}{c|}{ Std. Dev } \\
\cline { 2 - 7 } & Prior & Post & Prior & Post & Prior & Post \\
\hline Procurement Terminology & 1.22 & 2.16 & 1.00 & 2.00 & 0.72 & 0.59 \\
\hline Procurement Business Process & 1.43 & 2.14 & 1.00 & 2.00 & 0.82 & 0.56 \\
\hline Sales \& Distribution Terms & 1.57 & 2.33 & 2.00 & 2.00 & 0.65 & 0.56 \\
\hline Sales \& Distribution Processes & 1.61 & 2.33 & 2.00 & 2.00 & 0.71 & 0.56 \\
\hline Financial Terminology & 1.30 & 2.24 & 1.00 & 2.00 & 0.75 & 0.53 \\
\hline Financial Accounting Processes & 1.09 & 2.24 & 1.00 & 2.00 & 0.72 & 0.75 \\
\hline $\begin{array}{l}\text { Importance of integrated business } \\
\text { processes via ERP }\end{array}$ & 0.87 & 2.14 & 1.00 & 2.00 & 0.68 & 0.64 \\
\hline $\begin{array}{l}\text { Interdependencies between procurement, } \\
\text { sales, distribution }\end{array}$ & 1.04 & 2.14 & 1.00 & 2.00 & 0.75 & 0.64 \\
\hline $\begin{array}{l}\text { Ability to analyze integrated information } \\
\text { for managerial decision making }\end{array}$ & 1.30 & 2.14 & 1.00 & 2.00 & 0.69 & 0.71 \\
\hline $\begin{array}{l}\text { Ability to analyze individual employee } \\
\text { actions on operation of other functions }\end{array}$ & 1.43 & 2.33 & 1.00 & 2.00 & 0.82 & 0.64 \\
\hline
\end{tabular}

\section{Limitations and Conclusion}

The primary purpose of this study was to assess whether student knowledge of business processes was expanded during the usage of the paper game simulation. Based on feedback given during the self-assessment of surveys, it does appear that this may be the case. Though it appeared that students viewed the simulation as engaging and the instructor effective, it is also worth exploring the self-assessment section of prior- and post-test results. It should not be discounted that while self-perceived knowledge was shown to increase in all areas, this should be expected. Research has shown that learning occurs naturally because of participating in a simulation exercise [8].

That said, this study is a positive for the use of an activity based learning experience to develop a frame of reference for students as they proceed further into ERP concepts. Besides providing building blocks for business terminology and transactional data needed to support an ERP system, the paper game also serves as a team building activity. Teamwork and relationships created the paper game carried over into the course, and even execution of an end-of-semester SAP based distribution simulation from the ERPsim Lab. This is noteworthy as team composition and skills have been identified as being a critical success factor for ERP system implementations [10].

Another point of interest to observe in limitations would be in regard to the difference of teaching an ERP course with and without using the paper game as an introduction, researching significant differences between classes. By obtaining data in this manner, the importance of using the paper game as an enhancement may be observed more objectively. A possible method would be to compare the assessment differences between the face-to-face students playing the paper game to their online peers in the same course who do not participate in the game before using ERP software. The challenge is to control for the level of potential ERP experience with distance students in either business processes or ERP systems. 
Furthermore, while insight was gained, the opportunity to gain further beneficial research using a paper-based supply chain game may be garnered through pairing the self-assessment with an objective measure, such as grade analysis, to truly grasp what the impact of the paper game. However, this study gave the researchers insight on the benefits of using a paper-based supply chain game simulation prior to taking $18-22$ year-old students into an ERP course. Based on the data, students felt more confident after participating in the simulation, enjoyed the simulation itself, and felt that the instructor helped make the simulation effective. These are all essential keys to have a successful immersion into business simulations.

\section{References}

[1] A.M. Damewood, "Current trends in higher education technology: simulation," TechTrends, vol. 60 no. 3, pp. 268-271, March 2016.

[2] W.J. Shroer, "Generation X, Y, Z and the others," available at http://socialmarketing.org/archives/generations-xy-z-and-the-others/ [Accessed: July 18, 2017].

[3] Althouse, N.R., and Hedges, P.L., "Plan before you play: an activity for teaching the managerial process," Decision Sciences Journal of Innovative Education, vol. 13, no. 4, pp. 515-528, October 2015.

[4] R. Eskrootchi and G.R. Oskrochi, "A study of the efficacy of project-based learning integrated with computer-based simulation - STELLA," Journal of Educational Technology and Society, vol. 13 no. 1, pp. 236-245, January 2010.

[5] P. Rooney, "Students @ play: Serious games for learning in higher education," in International Technology, Education and Development, INTED 2007, Valencia, Spain, March 7-9, 2007, pp. 1-10.

[6] M. Darban, M. and G. Polites. "Do emotions matter in technology training? Exploring their effects on individual perceptions and willingness to learn," Computers in Human Behavior, vol. 62 pp. 644-657, September 2016.

[7] A. Grasas and H. Ramalhinho, "Teaching distribution planning: A problem-based learning approach," The International Journal of Logistics Management, vol. 27 no. 2, pp. 377-394, May 2014.

[8] P. Anderson, and L. Lawton, "Business simulations and cognitive learning: developments desires, and future directions," Simulation \& Gaming, vol. 40 no. 2, pp. 193-216, May 2008.

[9] P.M. Leger, J. Robert, G. Babin, D. Lyle., P. Cronan and P. Charland, "ERP simulation game: A distribution game to teach the value of integrated systems," Developments in Business Simulation and Experiential Learning, vol. 37, March 2010. 
[10] T. Cronan, and D. Douglas, "A student erp simulation game: A longitudinal study," Journal of Computer Information Systems, vol. 53 no. 1, pp. 3-13, February 2012.

[11] L. Chen, A. Keys and D. Gaber, "How does erpsim influence students' perceived learning outcomes in an information systems course? An empirical study," Journal of Information Systems Education, vol. 26, no. 2, pp. 135-146, Spring 2015.

[12] K. Alshare, M. El-Masri and P. Lane, "The determinants of student effort at learning erp: A cultural perspective," Journal of Information Systems Education, vol. 26, no. 2, pp. 117-133, Spring 2015.

[13] Y.C. Chang, H. Peng and H. Chao, "Examining the effects of learning motivation and of course design in instructional simulation game," Interactive Learning Environments, vol. 18, no. 4, pp. 319-339, December 2010.

[14] Y. Shen, J. Nicholson. And D Nicholson, "Teaching tip: using a group role-play exercise to engage students in learning business processes and erp," Journal of Information Systems Education, vol. 26, no. 5, pp. 265-280, January 2016.

[15] T. Cronan, L. Pierre-Majorique, R. Jacque, B. Gilbert and C. Patrick, "Comparing objective measures and perceptions of cognitive learning in an erp simulation game," Simulation \& Gaming vol. 43, no. 4, pp. 461-480 February 2012. 